Research Article

\title{
Preparation of Stick Type Solid Glue as Paper Adhesive Using Mixed Seaweed Extract
}

\author{
Seung-Jun $\mathrm{Oh}^{1}$, Won-Sik Han ${ }^{1}$, Koang-Chul Wi ${ }^{2}{ }^{*}$ \\ ${ }^{I}$ The Research Center of Conservation Science for Cultural Heritage, Hanseo University, Seosan 31962, Korea \\ ${ }^{2}$ Department of Cuitural Heritage Conservation, Hanseo University, Seosan 31962, Korea
}

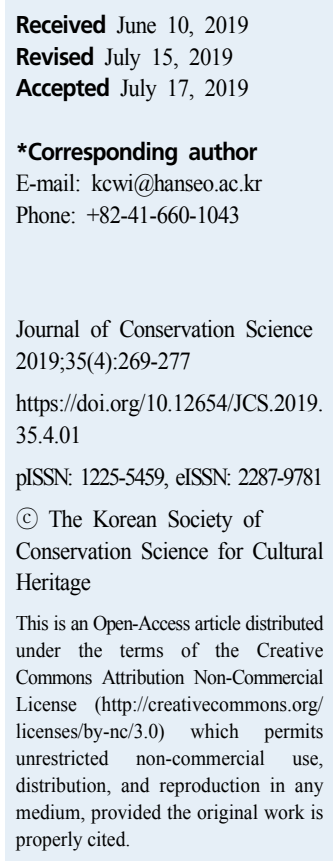

ABSTRACT Seaweed extracts, namely carrageenan obtained from Grateloupia elliptica and algin obtained from Laminaria, were employed as adhesive agents to synthesize solid adhesives for paper. Carrageenan from Grateloupia elliptica with the highest adhesive strength and lgin from Laminaria with the highest compressive strength was selected. The selected carrageenan and algin were mixed in a ratio of 7:3, and the mixture was employed as an adhesive agent. At a high temperature, sodium stearate(used as a solidifying material) oxidized the seaweed extracts. Consequently, carrageenan and algin were added to the final manufacturing process. The adhesive strength of the final synthesized solid adhesive is found to be $3.02 \mathrm{MPa}$ and the compressive strength is found to be $30.5 \mathrm{~N}$. Compared to the adhesive strength $(2.95 \mathrm{MPa})$ and compressive strength $(30.11 \mathrm{~N})$ of commercial solid adhesives, the obtained results indicate superior adhesion characteristics. Furthermore, the proposed adhesive is environment-friendly because the presence of volatile organic compounds, formaldehyde, and heavy metals(such as chromium, lead, and cadmium) were not detected. Moreover, when used, the flatness of paper was twice that of commercial solid paper adhesives. Hence, the proposed adhesive can provide excellent adhesion, stability, and usability.

Key Words Paper glue, Seaweed extract, Adhesive material, Solid adhesive, Natural materials

\section{INTRODUCTION}

Seaweed polysaccharides and other marine biopolymers have been studied for a variety of applications in pharmaceutical, bio-biotechnology, and new materials industries(Shahidi and Han, 1993; Moreton and Armstrong, 1998). In particular, carrageenan, which is an extract from Grateloupia elliptica, is a water-soluble galactose polymer of red algae and is generally used in food and pharmaceutical industries as a gelator, stabilizer, and thickener. Carrageenan has a disaccharide negative charge in red algae. It has the flexibility to maintain its structure in the severe sea waves. This substance is highly flexible and helps reinforce the surrounding structures(Grazela and Morrison, 2003).
Carrageenan has been studied to fabricate water vapor permeable films(Rhim et al., 1996), surface coating materials (Rhim et al., 1998), packaging(Park et al., 1998; Ha et al., 2015), anti-inflammatory additives(Woo et al., 2010) in the medical field, and improve the strength of human tissue(Ha et al., 2015) in the food industry. Furthermore, many of the findings in these studies have already been commercialized. Alginic acid is known as one of the constituents of the brown algae. It is a co-polysaccharide composed of D-mannuronic acid and L-guluronic acid monomers. Na-alginate, which is found in nature, is a water-soluble nontoxic polysaccharide and is known as an excellent biocompatible substance(Cha et al., 2002). 
These substances have been used in optical films for microorganisms, pharmacological carriers(Lai et al., 2003), and membranes(Perron et al., 2002). Alginic acid with low molecular is used to suppress adipocyte differentiation(Park et al., 2015) and senescence(Choi et al., 1992) in the biomedical field. It has been used also in the agricultural field as an application composite material for eco-friendly farm materials (Kang and Jung, 2016) and as an adsorbent and a material that can be used for qualitative and quantitative analyses(Choi and Choi, 2004; Kang et al., 2011). Particularly, studies in which alginate and carrageenan are used together or are combined to make a new material have been actively conducted. The objectives of such studies have been to bring together the complementary components of the two to maximize their properties(Roh and Shin, 2006).

There have been attempts to use the seaweed powder as an adhesive material to repair concrete(Lee et al., 2017). Seaweed has been used as an enhancer for treating clay wall structures, a reinforcing agent, an adhesive in Korean paper, and plaster using soil or sludge(Kim et al., 2017). In previous studies, liquid adhesives using polysaccharides extracted from red and brown algae were fabricated and their adhesivities were confirmed by applying them to various applications.

In those studies, it was found that out of the polysaccharides of 8 species -4 brown and 4 red algae - the adhesivities of Grateloupia elliptica carrageenan from the red algae and the seaweed algin from the brown algae were very good. However, it was also found that the thickening factor, which is an advantage of these algae, was causing a problem in the liquid-type adhesive. Strength degradation occurred in the stick-type adhesive owing to its thickening and gelation. However, if this problem could be overcome, the stick-type adhesives would have better adhesion properties and utility (Han et al., 2018).

The stick-type adhesive was developed and commercialized by Henkel AG \& Company(DEU) for the first time in 1969. As the rotationally protruding case of the glue was actualized (Cognard, 2006), its application was accelerated. Various polymers have been studied and used as formulations for solid adhesives. In addition to the well known study on developing the adhesive using polyvinylpyrrolidone(Buhler, 2005), studies on polyurethane(Gierenz et al., 1994) and polyvinylactate (Dickmann et al., 1982) were conducted. These studies either were commercialized or influenced commercial products.
The stick-type adhesive is a solid adhesive made of a water-soluble carrier, an adhesive component, a formulation agent, a formulating agent, and a supplement such as a moisturizing agent or stabilizer. These substances are made to react or mixed at a high temperature and injected into a rotationally protruding tube. Recently, formulation supplements, adhesive supplements, and formulating supplements have been added to improve the physical properties of the stick-type adhesive. The advantage of the stick-type adhesive is that it does not contaminate the surroundings, because it does not flow or spill like a liquid. Therefore, it consumes less adhesive, is convenient to use, and produces fewer wrinkles in paper.

As a result, many paper adhesives have been replaced with the stick-type adhesive or stick glue. Although polyvinylpyrrolidone exhibits adhesivity, it is mainly used as a formulation agent for maintaining the solid form, and sodium stearate and formulating agents are added to solidify it(Mestetsky and $\mathrm{Pa}$, 1974; Sitaramiah and Jorgensen, 1995; Jiang et al., 2006).

In this study, polyvinylpyrrolidone and sodium stearate were used as formative agents and formulating agents, respectively, and seaweed extract was used as an adhesive agent to prepare a sticky adhesive. This sticky adhesive was fabricated to improve the physical properties of the existing commercial stick-type adhesives in respect of their adhesive strength, compressive strength, and smoothness. Efforts were made to develop the fabrication process and overcome solidification problems owing to the use of seaweed polysaccharide. Furthermore, to fabricate eco-friendly stick-type adhesives that are harmless to the human body, materials such as heavy metals, volatile organic compounds, and formaldehyde were excluded from the fabrication process. Finally, the proposed eco-friendly stick-type adhesives were used for the preservation and restoration of paper crafts to check and confirm their being useful for the purpose.

\section{MATERIALS AND METHODS}

\subsection{Reagents and instruments}

Polyvinylpyrrolidone 30(PVP-30), polyvinylpyrrolidone 90 (PVP-90), sucrose, glycerin, ethylene glycol, stearic acid, oleic acid, polyvinylalcohol(PVA), Triton X100, and ethyl alcohol were procured from Samchun Chemicals(KOR), and propylene glycol and sodium stearate were procured from Aldrich 
Chemicals(USA). Polyvinylpyrrolidone 120(PVP-120, average molecular weight $1,300,000)$ and polyvinylpyrrolidone 300 (PVP-300, average molecular weight 3,000,000) were procured from Shyuanye(CHN), FD330A was procured from Saehan Silichem(KOR), and Napre was procured from Saero Hands (KOR). The MS-CB404(LKLABKOREA, KOR) heating mantle was used as a heater, and the heating temperature was controlled using TC-200P(M-TOP, KOR). The strength of the adhesive was measured using a tensile strength meter equipped with a PGN20(Schunk, DEU) push-pull and a jig for a paper tensile test, and the compressive strength was measured using a Uniaxial Instron 5542(Instron, USA). The smoothness of the paper after bonding was measured using L\&W Bendtsen Tester(Lorentzen \& Wettre, SWE). To evaluate the toxicity of the stick adhesive, the cadmium content was measured using inductively coupled plasma-mass spectrometer (ICP-MS)(Nexion 2000 B, PerkinElmer, USA), lead and chromium contents were measured using Optical Emission Spectrometry (OES)(Optima 8300, PerkinElmer, USA), ethylbenzene and xylene contents were measured using gas chromatography-mass spectrometry (GC-MS)(7890B, Agilent, USA), formaldehyde content was measured using high performance liquid chromatography (HPLC)(Altus A-10, Perkin Elmer, USA), and benzene and toluene contents were measured using Clarus 600(PerkinElmer, USA).

\subsection{Extraction and bleaching of seaweed polysaccharide}

Four types of brown algae - sea trumpet, kelp, rhubarb, and sea mustard-and four types of red algae-Grateloupia elliptica, agar, glue plant, and sea staghorn-were extracted using $1.0 \% \mathrm{~K}_{2} \mathrm{CO}_{3}$ aqueous solution, Which is 80 times distilled water of a seaweed used, at $100^{\circ} \mathrm{C}$ for $4 \mathrm{~h}$, and seaweed polysaccharides were extracted using ethyl alcohol (Han et al., 2018).

The extracted seaweed polysaccharide was bleached using a $3.0 \% \mathrm{NaClO}$ aqueous solution, which is more than 40 times of the extracted seaweed polysaccharide, at room temperature. It was bleached three times for $2 \mathrm{~min}$ each using a stirrer equipped with a high-speed impeller, and the seaweed polysaccharide was precipitated using ethyl alcohol and dried and pulverized before use(Korea Research Institute of Bioscience and Biotechnology, 1982).

\subsection{Fabrication of stick-type adhesive}

The stick-type adhesive was fabricated by first dissolving the various types of PVP formulation agents in distilled water and ethyl alcohol, then adding a humectant, defoamer, natural preservative, surfactant, and some sucrose to a three-phase separation reaction, in which the reflux condenser, temperature control sensor, and spinning impeller could be inserted. This was followed by heating the mixture at $70-90^{\circ} \mathrm{C}$ to fabricate the adhesive. The following procedures were carried out as the solution became clear and uniform.

The solid adhesive was fabricated by pouring the mixture, at a high temperature at which flowability could be maintained, into a screw-type lip balm mold of $15 \mathrm{~mm}$ diameter and 90 $\mathrm{mm}$ height. The mold was then stored at room temperature for a minimum of $48 \mathrm{~h}$ for stabilization of its contents. Finally, the material properties of the adhesive were measured(Figures 1 and 2).

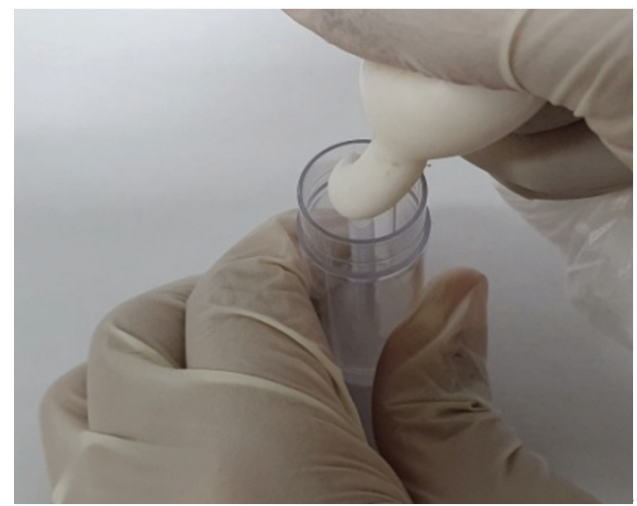

Figure 1. Manufacture using screw mold.

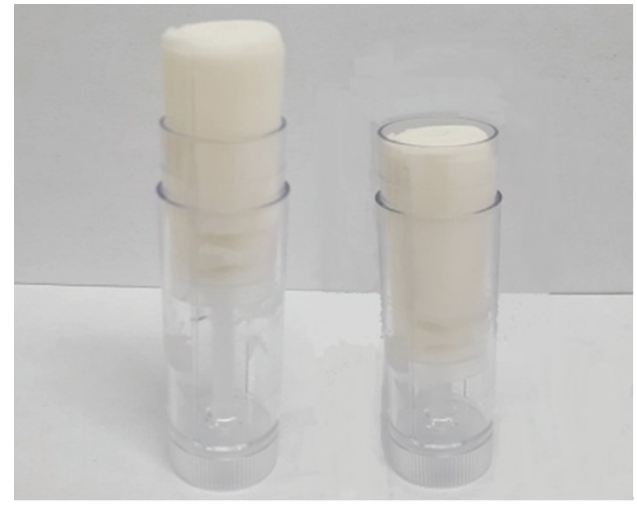

Figure 2. Stick type adhesive. 


\subsection{Material properties of stick-type adhesive}

Because an adhesion test method for paper is not available, the adhesion strength of the paper was tested by using a modified test method for KS G2105(2014)-office glue-. One side of a $4 \times 6 \mathrm{~cm}$, basis weight is $80 \mathrm{~g}$, was bonded to a $150 \mathrm{~g}$ coated paper at a high temperature, and the uncoated side of the paper was glued using the adhesive. The bonded paper specimen was dried in a dryer at $35^{\circ} \mathrm{C}$ for at least $24 \mathrm{~h}$. The dried specimen was cut into $30 \mathrm{~mm} \times 90 \mathrm{~mm}$ rectangle and they were overlapped by $30 \mathrm{~mm}$. The unbonded specimens on both sides were fixed by paper jigs to be tested.

The compressive strength of a cylindrical solid adhesive sample of $15 \mathrm{~mm}$ diameter and $16 \mathrm{~mm}$ height was measured using a $40 \mathrm{~mm}$ load cell at $200 \mathrm{~mm} / \mathrm{min}$ up to $12.8 \mathrm{~mm}$ (Wang et al., 2012). The smoothness of the sample was measured in accordance with KS M ISO 187(2016) paper, board, and pulps, standard conditioning and managing the standard conditioning for humidity treatment and testing $\left(23 \pm 1^{\circ} \mathrm{C}, 50 \pm 2 \% \mathrm{RH}\right)$ - and in accordance with KS M ISO8791-2(2016) - determination of roughness/smoothness for paper and board using air leak methods; the Bendtsen method-. The same amounts of the proposed stick-type and commercial stick-type adhesives were uniformly coated on a commercially available $80 \mathrm{~g}$ A4 paper on a rubber plate within 2 min using a metal roller. The same kind of A4 paper was bonded to the coated surface, and then a $30 \mathrm{~mm}$ strip on each side of the paper was cut. After that, the smoothness was measured by pressing it with $10 \mathrm{~kg}$ of metal at $25^{\circ} \mathrm{C}$ for at least $48 \mathrm{~h}$.

After the stick-type adhesive was fabricated, the amounts of lead(quantitative limit $4 \mu \mathrm{g} / \mathrm{g}$ ), cadmium(quantitative limit of $1 \mu \mathrm{g} / \mathrm{g}$ ), chromium(quantitative limit of $2.5 \mu \mathrm{g} / \mathrm{g}$ ), ethyl benzene(detection limit of $0.00025 \%$ ), formaldehyde(quantitative limit of $40 \mu \mathrm{g} / \mathrm{g}$ ), benzene(detection limit of $0.00002 \%$ ), toluene(detection limit of $0.00002 \%$ ), and xylene(detection limit of $0.0006 \%$ ) were measured.

\section{RESULTS AND DISCUSSION}

The general stick-type adhesive use PVP, polyurethane, polyvinyl acetate, urea, or water-soluble epoxy, among which PVP is known to be the most popular and exhibits excellent properties. However, to maintain the adhesive properties of the stick-type adhesive based on the seaweed polysaccharide, when using polymers other than PVP or using other formulation auxiliaries, the adhesive strength is very low. The average adhesive strength of the solid adhesive using sucrose as the formulation and adhesion supplement $(9 \mathrm{~g}$ of distilled water, $3 \mathrm{~g}$ of PVP K-90, $5 \mathrm{~g}$ of sucrose, $2.1 \mathrm{~g}$ of glycerin, and $1.4 \mathrm{~g}$ of sodium stearate) was $0.26 \mathrm{MPa}$, and its self-compressive strength was approximately $31.4 \mathrm{~N}$. However, when the seaweed polysaccharide was included in its composition, the compressive strength was reduced. In particular, when the content of the seaweed extract exceeded $9 \%$, it did not perform as a stick-type adhesive(Figure 3 ).

The self-hardness of the adhesive was reduced when the amount of the formulating agent(sodium stearate, PVP K-90, or sucrose) was increased. In this case, even though the self-compressive strength, spreadability, and formability of the adhesive decreased considerably, the amount of seaweed polysaccharide was increased. As a result, the bond strength increased linearly and the adhesive strength of the polysaccharide content increased from $0.26 \mathrm{MPa}$ to $3.89 \mathrm{MPa}$. This was because the characteristics of the seaweed polysaccharides weakened the self-strength during the process of PVP formulation; however, it seemed that the adhesive strength of seaweed polysaccharide increased because of the high adhesivity of added seaweed polysaccharide.

Most of the seaweed polysaccharides can maintain a high adhesiveness. However, if the viscosity of the seaweed polysaccharide is increased so much that it can be used as a normal thickener, it will take the form of jelly. Therefore, it may not be suitable for the stick-type adhesive. Moreover, at high temperatures, sodium stearate(including oleic acid and stearic acid), which is used as the formulating agent, promotes the oxidation of seaweed polysaccharides, and seaweed polysaccharides must be added at the final stage. As such, the mixing process will not be possible from the beginning of the reaction. Therefore, the temperature and the mixing order of the contents during the fabrication are very important factors to fabricate the stick-type adhesive with the seaweed extract (Figure 4).

The eight extracted polysaccharides(four each from brown and red algae) are in the form the alginic acid and galactan, respectively. Because all eight types exhibit a thickening effect in the presence of water, this causes not only a change in the compressive strength of the adhesive but also a problem in the moisturizing agent included in the stick adhesive. As a result, 


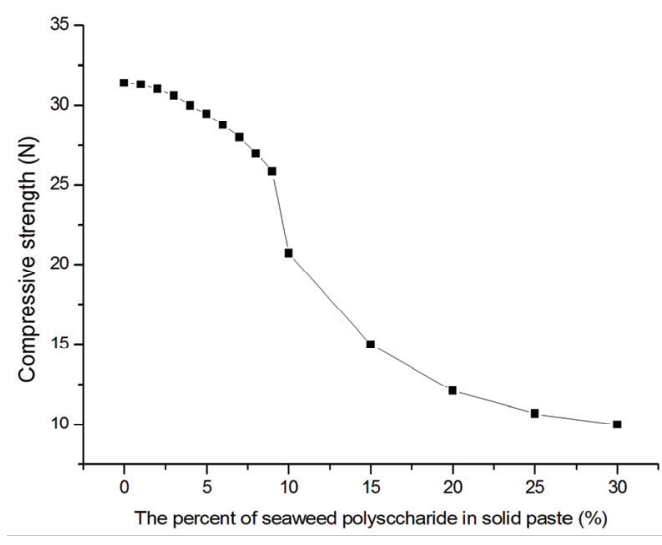

Figure 3. Change in compressive strength of solid adhesive with addition of seaweed polysaccharide.

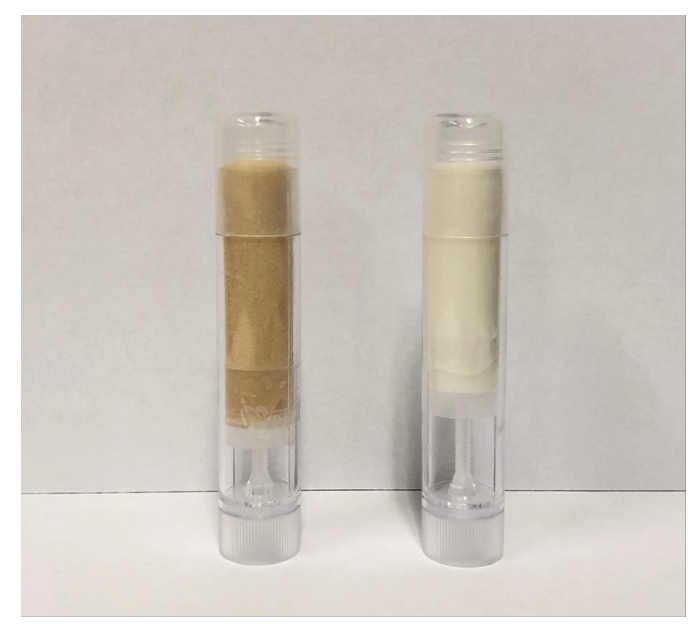

Figure 4. Oxidation of stick adhesive at high temperatures because of formulation material(browning reaction, the left).

using $1 \%$ or more glycerin or ethylene glycol reduced the strength, which appeared to be because of the seaweed. As shown in Figure 5, only propylene glycol showed a negligible decrease in compressive strength up to $4 \%$. Therefore, only propylene glycol should be used as a moisturizer.

PVP was not possible to use with a low strength at a low molecular weight such as K-30, and the self-compressive strength could be maintained by using PVP that exceeds K-120 or K-90 with a molecular weight of 1,200,000. Although PVP K-300 increased the adhesive strength and compressive strength, its solubility was so low that problems with the degree of mixing occurred persistently during fabrication.

To address these problems, the application tests of the

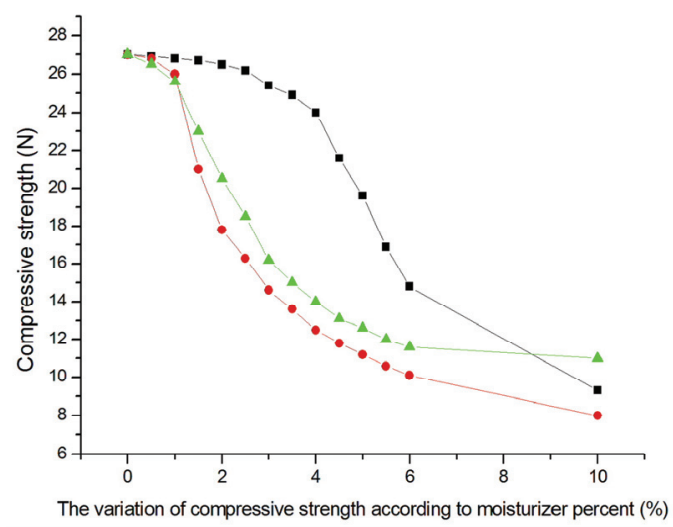

Figure 5. Variation in compressive strength versus the amount of moisturizer. (- - - propylene glycol, - $\boldsymbol{\Delta}$ - ethylene glycol, - - - glycerin)

alcohols used in some literature were conducted. However, in most tests, alcohol evaporated within a short span of time after fabrication, or many surfactants were needed with relatively high molecular alcohol IPA. PVA and PVAc, which are added to general commercial stick-type adhesives, also have low strength or polysaccharide oxidation owing to the added seaweed polysaccharide. Less than $10 \%$ seaweed polysaccharide content should be used in the mixture to overcome this problem. Therefore, it was confirmed that the application range of the solid adhesive using seaweed polysaccharide is very narrow.

The property of the stick-type adhesives using seaweed polysaccharides is determined by the self-strength, degree of application, degree of adhesion, and shape and physical properties of the adhesive after fabrication. Accordingly, sticktype adhesives with various compositions were fabricated. The bonding and compressive strengths of the adhesive were the most important considerations in this process. To achieve these twin objectives, we used 17-25 g of distilled water, 4-15 g of ethyl alcohol, $0.5-5 \mathrm{~g}$ of propylene glycol, 2-8 $\mathrm{g}$ of sucrose, 3-7 $\mathrm{g}$ of PVP K-120, 1-5 $\mathrm{g}$ of sodium stearate, $0.03 \mathrm{~g}$ of surfactant(Triton X100), and $1.50 \mathrm{~g}$ of Napre. A maximum of $30 \%$ of seaweed polysaccharide content was added to the solution, which did not consider distilled water and ethyl alcohol.

Table 1 shows the adhesive and compressive strengths of stick-type adhesives fabricated using PVP K-120. The adhesive strength of red algae containing sample was significantly higher than that of conventional commercial liquid adhesives and commercial stick adhesives; however, the adhesive strength of brown algae containing sample was lower than that 
Table 1. Adhesive and compressive strengths of stick adhesives made with red algae and brown algae polysaccharides

\begin{tabular}{|c|c|c|c|c|c|c|c|c|c|c|}
\hline & $\begin{array}{l}\text { Liquid } \\
\text { adhesive }\end{array}$ & $\begin{array}{c}\text { Stick } \\
\text { adhesive }\end{array}$ & $\begin{array}{l}\text { Pachymeniopsis } \\
\text { elliptica }\end{array}$ & $\begin{array}{l}\text { Gelidiumamansii } \\
\text { lamouroux }\end{array}$ & $\begin{array}{l}\text { Gloiopeltis } \\
\text { tenax }\end{array}$ & $\begin{array}{l}\text { Codium } \\
\text { fragile }\end{array}$ & $\begin{array}{l}\text { Ecklonia } \\
\text { cava }\end{array}$ & Laminaria & $\begin{array}{r}\text { Eisenia } \\
\text { bicyclis }\end{array}$ & $\begin{array}{c}\text { Undaria } \\
\text { pinnatifida } \\
\text { suringar }\end{array}$ \\
\hline $\begin{array}{c}\text { Adhesive } \\
\text { strength } \\
\text { (MPa) }\end{array}$ & 1.81 & 2.11 & 3.50 & 2.62 & 2.80 & 2.69 & 1.64 & 2.36 & 0.98 & 1.89 \\
\hline $\begin{array}{l}\text { Compressive } \\
\text { strength (N) }\end{array}$ & - & 30.11 & 28.44 & 24.69 & 24.54 & 25.82 & 32.54 & 39.84 & 38.12 & 30.22 \\
\hline
\end{tabular}

of commercial stick adhesives(Figures 6 and 7).

Contrary to the results of adhesive strength, the stick-type adhesives using red algae showed a lower compressive strength than the conventional stick-type adhesives and those using brown algae showed an excellent compressive strength.

Although the adhesive strength of the stick-type adhesive using red algae Grateloupia elliptica carrageenan was the highest at $3.50 \mathrm{MPa}$, this adhesive showed a lower adhesive strength at $28.11 \mathrm{~N}$ when compared with the compressive strength of the commercial stick adhesive, which was $30.11 \mathrm{~N}$. In the case of the brown algae, while the compressive strength of the solid adhesive using kelp algae was $39.84 \mathrm{~N}$, which was higher than that of the commercial stick adhesive, the adhesive strength decreased to $2.36 \mathrm{MPa}$.

To address this problem, a solid adhesive was prepared by mixing galactan-based carrageenan and kelp algin, which are extracts of red algae Grateloupia elliptica, in a certain ratio. The adhesive and compressive strengths of the adhesive based on this mixture are shown in Figure 8. As the stick-type adhesives were fabricated by varying the ratio of Grateloupia elliptica and kelp extracts from 100:0 to 0:100 at an increment of $10 \%$, it was found that their adhesive and compressive strengths were higher than the commercially available sticky adhesive when the ratio was $70: 30( \pm 2.0)$. When this ratio was used to fabricate the stick-type adhesive, the stick-type adhesive exhibited excellent adhesive and compressive strengths and had very good flowability.

Based on these results, the best composition of the sticky adhesive using the most stable and sustainable seaweed extract was $25 \mathrm{~g}$ of distilled water, $10 \mathrm{~g}$ of ethyl alcohol, $0.50 \mathrm{~g}$ of propylene glycol, $2.50 \mathrm{~g}$ of sucrose, $7.0 \mathrm{~g}$ of PVP K-120, sodium stearate, $0.02 \mathrm{~g}$ of surfactant(FD330A), $0.02 \mathrm{~g}$ of surfactant

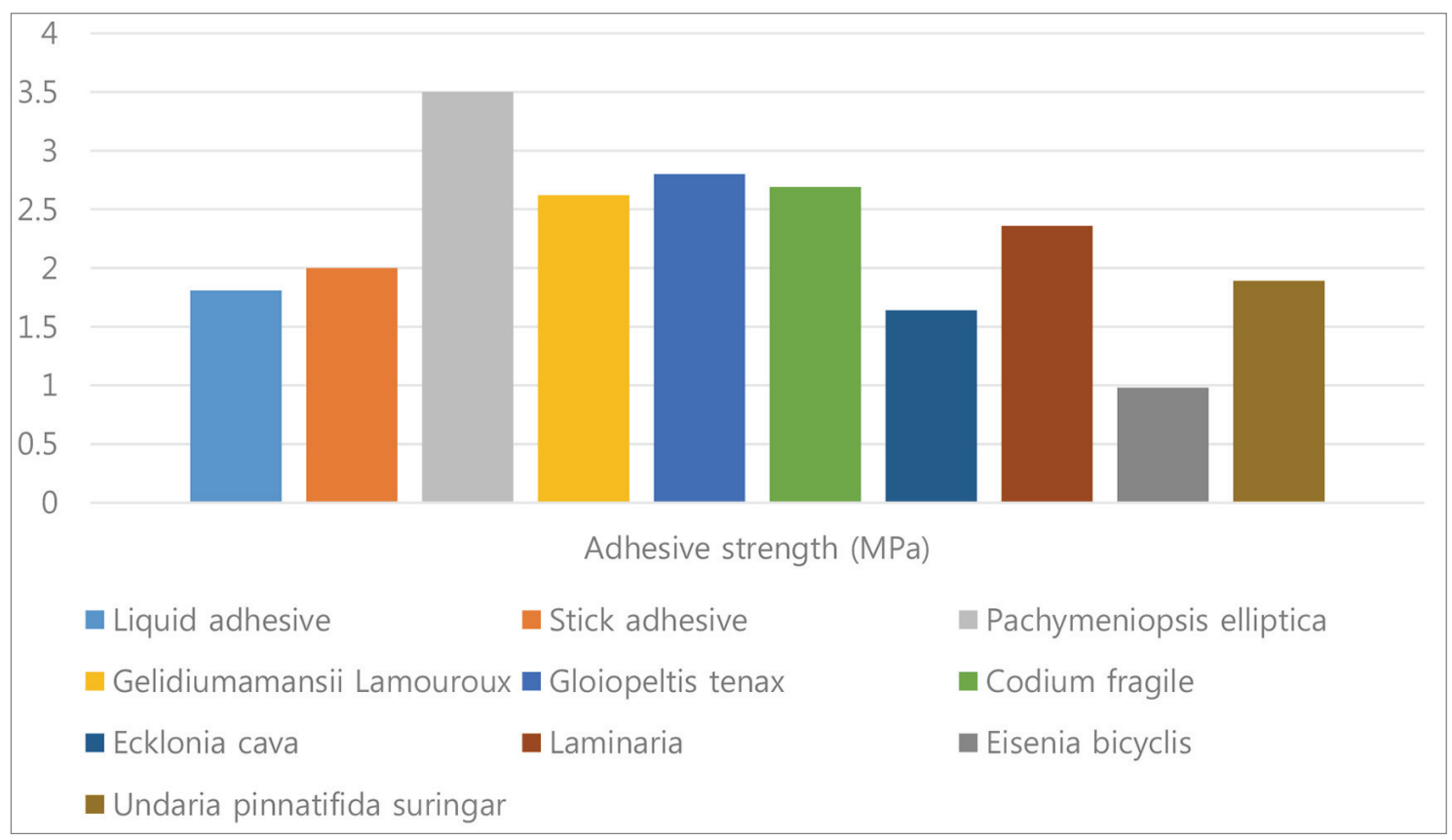

Figure 6. Adhesive strengths of stick adhesives made from red algae and brown algae polysaccharides (MPa). 


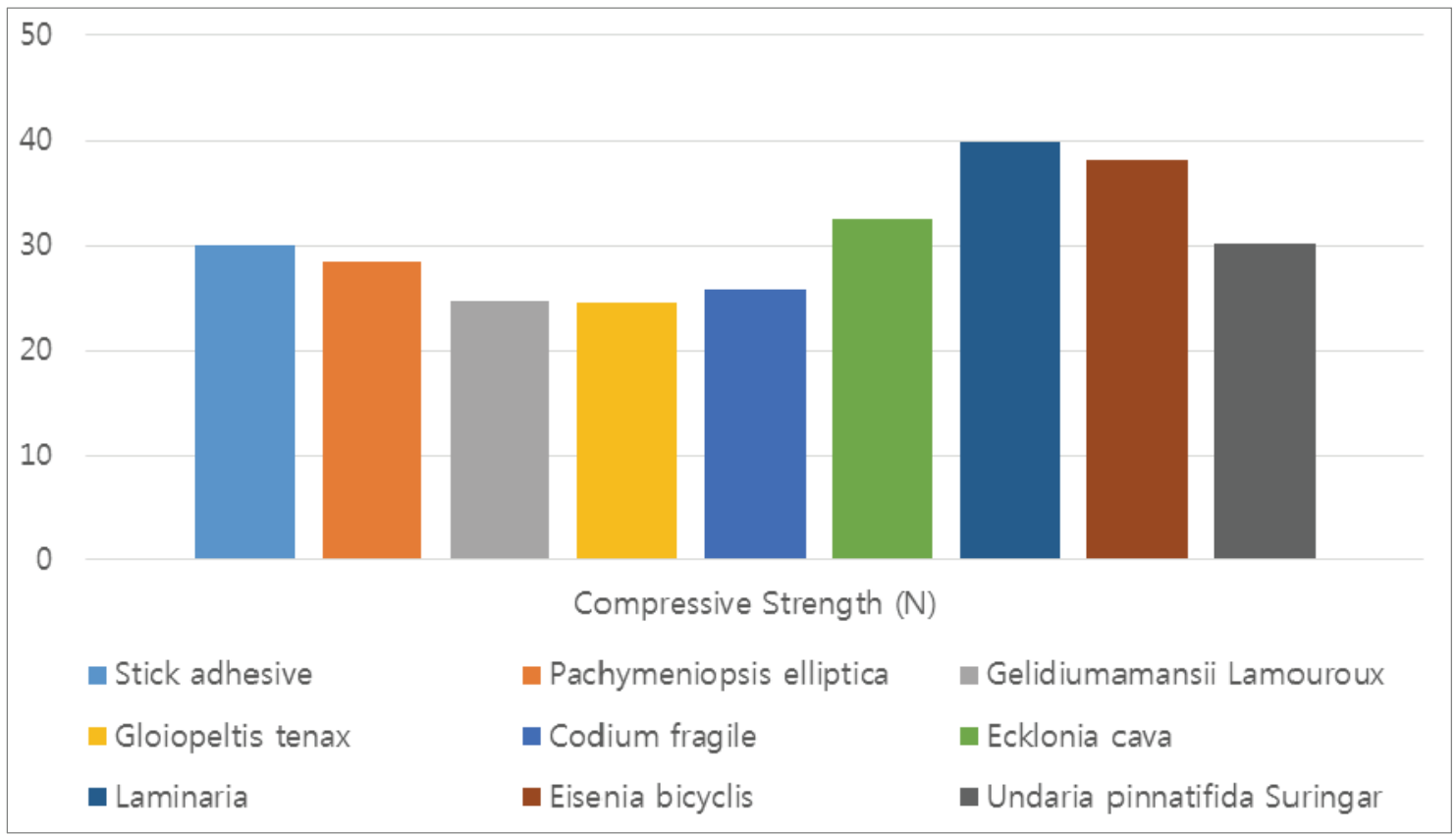

Figure 7. Compressive strengths of stick adhesives made from red algae and brown algae polysaccharides $(\mathrm{N})$.

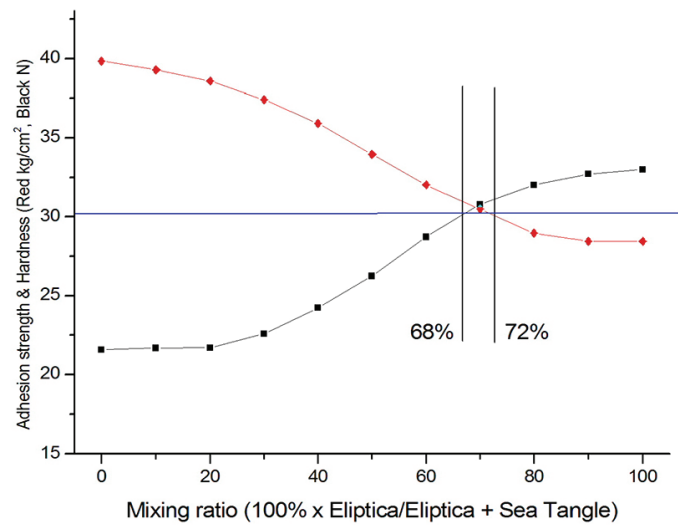

Figure 8. Adhesive and compressive strengths of stick adhesive according to mixing ratio of Pachymeniopsis elliptica and Laminaria extracted polysaccharides.

(Tripton X100), $1.50 \mathrm{~g}$ of Napre, $4.55 \mathrm{~g}$ of Grateloupia elliptica extract polysaccharide carrageenan, and $1.95 \mathrm{~g}$ of kelp algin. Excluding the amounts of distilled water and alcohol used, the seaweed extract was approximately $30.04 \%$ of the solid adhesive, and the ratio of carrageenan to kelp algin was 7:3.

For the preparation of these solutions, $7 \mathrm{~g}$ of PVP K-120 was added to a solution consisting of $15 \mathrm{~g}$ of distilled water and $10 \mathrm{~g}$ of ethyl alcohol, which was stirred at $80^{\circ} \mathrm{C}$ for 30 $\min$. Next, $0.02 \mathrm{~g}$ of FD330A and $0.02 \mathrm{~g}$ of Triton X-100 were added. After the solution was maintained at $80^{\circ} \mathrm{C}$ for $30 \mathrm{~min}$ and until it was uniform, the solution was heated to $90^{\circ} \mathrm{C}$ and $3.60 \mathrm{~g}$ of sodium stearate was added. After approximately $1 \mathrm{~h}$, a uniform solution was again obtained.

When the viscosity of the solution was increased by evaporation of alcohol after the cooling condenser was eliminated, $10 \mathrm{~g}$ of distilled water, $1.50 \mathrm{~g}$ of Napre, $0.50 \mathrm{~g}$ of propylene glycol, $2.50 \mathrm{~g}$ of sucrose, $4.55 \mathrm{~g}$ of carrageenan, and $1.95 \mathrm{~g}$ of kelp algin were added and uniformly mixed to make a paste. Finally, the solution was stirred at $300 \mathrm{rpm}$ or slower for $15 \mathrm{~min}$.

In this process, when sodium stearate was added, the temperature and time increased, oxidation(discoloration) of the seaweed extracts occurred. As a result, a uniform stick-type adhesive did not form, and the adhesive and compressive strengths of the adhesive decreased significantly. When the stirring speed was higher than $500 \mathrm{rpm}$, microbubbles were present in the stick-type adhesive even in the presence of the defoaming agent, which may have caused the compressive and adhesive strengths to decrease. The flatness of the fabricated stick-type adhesive after use on paper(top 117.8-204.2, back $115-164 \mathrm{~mL} / \mathrm{min}$ ) was twice as high as that of the existing commercial stick-type adhesive(top 332.8, back $368 \mathrm{~mL} / \mathrm{min}$. Therefore, propylene glycol, which was used as a moisturizer, 
showed not only excellent formulation stability but also excellent smoothness. The hazard tests detected no heavy metals such as lead, cadmium, and chromium, though volatile organic compounds such as ethyl benzene, formaldehyde, benzene, toluene, and xylene were detected. Therefore, the proposed adhesive can be used as an eco-friendly stick-type adhesive.

In addition, this adhesive had no change in properties for more than 6 months after the preparation and the shrinkage or strength did not change. In particular, when the composition is changed simply by the user, the compressive strength and the adhesive strength can be adjusted, so that a stick-type adhesive having high usability can be produced. and it can be applied to wooden, fiber and leather adhesives as well as paper adhesives.

\section{CONCLUSIONS}

Seaweeds have been used to fabricate traditional glues such as starch paste, glue, and fish paste. Their sourcing location, preprocessing process, and extraction process have been modified to suit various uses and adherent materials. It is difficult to use the traditional glue without spilling it or wastage unless the user is skilled enough. Moreover, since they are natural materials, corruption has progressed and it has been disadvantageous to use for a long time. Therefore, this study fabricated an adhesive for paper craft based on polysaccharides of seaweed. The fabricated stick-type paper adhesive has good usability, is easy to store, and has physical properties similar to the conventional paper glue paste. While two types of seaweed polysaccharides were used as the adhesive agent, PVP-120 was used as a formulation agent, propylene glycol was used as a moisturizing agent, and sodium stearate was used as a formulation agent to fabricate the solid adhesive. The seaweed polysaccharides were mixed with kelp algin, which shows good compressive strength, and carrageenan, which shows good adhesion strength, in the ratio of 3:7. The resultant paste was used as an adhesive agent. The components were mixed at the end of the reaction to prevent high-temperature oxidation caused by the formulation agent.

Various stick-type adhesives were fabricated, among which the most stable and reliable seaweed-extract-based stick-type adhesive was the one fabricated by mixing a homogeneous solution of $15 \mathrm{~g}$ of distilled water, $10 \mathrm{~g}$ of ethyl alcohol, $7 \mathrm{~g}$ of PVP K-120, $0.02 \mathrm{~g}$ of FD330A, $0.02 \mathrm{~g}$ of Triton X-100, and $3.60 \mathrm{~g}$ of sodium stearate with a paste of $10 \mathrm{~g}$ of distilled water, $1.50 \mathrm{~g}$ of Napre, and $0.50 \mathrm{~g}$ of propylene glycol.

The adhesive strength of the stick-type adhesive was $3.02 \mathrm{MPa}$, and its compressive strength was $30.5 \mathrm{~N}$. It was confirmed that there was no change in its physical properties for at least 6 months after its fabrication. This bio-adhesive for paper craft was developed using natural materials. The total volatile organic compounds, $\mathrm{HCHO}$, and heavy metal analyses showed that the product posed no health risks.

To summarize, the baseline material composition for fabricating a seaweed paste for universal use was found, and it was verified that it can be used as an adhesive material for preservation and restoration of modern and ancient paper and paper crafts. Based on these findings, it is possible to develop general-purpose stick-type adhesives for use with materials other than paper.

\section{ACKNOWLEDGMENTS}

This work was supported by 2019 Cultural Technology Research and Development (Designated assignment) Project (No. R2018020045).

\section{REFERENCES}

Buhler, V., 2005, Polyvinylpyrrolidone excipients for pharmaceuticals. Springer, Heidelberg.

Cha, D.S., Choi, J.H., Chinnan, M.S. and Park, H.J., 2002, Antimicrobial films based on Na-alginate and K-carrageenan. LWT-Food Science and Technology, 35(8), 715-719.

Choi, J.H., Kim, I.S., Kim, J.I. and Yoon, T.H., 1992, Studies on anti-aging action of brown algae(Undaria pinnatifida): 2. Dose effect of alginic acid as modulator of anti-aging action in liver membranes. Journal of the Korean Fisheries Society, 25(3), 181-188. (in Korean with English abstract)

Choi, J.M. and Choi, S.D., 2004, Preconcentration and determination of trace copper(II) and lead(II) in aqueous solutions by adsorption on Ca-alginate bead. Journal of the Korean Chemical Society, 48(6), 590-598. (in Korean with English abstract)

Cognard, P., 2006, Handbook of adhesives and sealants. Elsevier, Amsterdam, 2.

Dickmann, H.H., Hechenberger, D. and Krattner, R., 1982, U.S. Patent No. 4,325,855. Washington, DC: U.S. Patent and Trademark Office. 
Gierenz, G., Klauck, W., Hoefer, R. and Gruetzmacher, R., 1994, U.S. Patent No. 5,371,131. Washington, DC: U.S. Patent and Trademark Office.

Grazela, A.J. and Morrison, N.A., 2003, U.S. Patent No. 6,586,032. Washington, DC: U.S. Patent and Trademark Office.

Ha, S.R., Choi, J.S. and Jin, S.G., 2015, Effects of extender on the tissue properties of MDCM hydrolyzate and carrageenan added emulsified pork sausage. Korean Society of Poultry Science, Daejeon, November 13, 24-35. (in Korean with English abstract)

Han, W.S., Oh, S.J., Kim, Y.M., Lee, Y.J., Kim, Y.J., Park, M.S. and Wi, K.C., 2018, Base study related with development of natural bio-adhesives using seaweeds. Journal of Conservation Science, 34(6), 595-604. (in Korean with English abstract)

Jiang, Y., Yan, Y.B. and Zhou, H.M., 2006, Polyvinylpyrrolidone 40 assists the refolding of bovine carbonic anhydrase B by accelerating the refolding of the first molten globule intermediate. Journal of Biological Chemistry, 281(14), 9058-9065.

Kang, H.R. and Jung, W.J., 2016, Manufacture and application of chitosan-alginate beads for development of environmentally-friendly agricultural material. Journal of Chitin and Chitosan, 21(3), 158-165. (in Korean with English abstract)

Kang, J.K., Lee, C.G., Park, J.A., Kim, J.H., Lee, I. and Kim, S.B., 2011, Phosphate adsorption on Fe-doped alginate beads. Proceedings of the Korean Society of Agricultural Engineers Conference, 211-211. (in Korean)

Kim, S.H., Lee, H.S. and Han, K.S., 2017, A study on the application of Dobak-glue for fixation painting layer of earthen mural. Journal of Conservation Science, 33(6), 553-564. (in Korean with English abstract)

Korea Research Institute of Bioscience and Biotechnology, 1982, Development of production technology of algin and protein of seaweed. 1-35. (in Korean)

Lai, H.L., Khalil, A.A. and Craig, D.Q.M., 2003, The preparation and characterisation of drug-loaded alginate and chitosan sponges. International Journal of Pharmaceutics, 251(1-2), 175-181.

Lee, P.W., Kim, E.K. and Kang, C.G., 2017, Study on a concrete repair material mixed with seaweed powder. Journal of The Korean Society for Urban Railway, 5(4), 1035-1043. (in Korean with English abstract)
Mestetsky, T.S. and Pa, E., 1974, U.S. Patent No. 3,817,887. Washington, DC: U.S. Patent and Trademark Office.

Moreton, R.C. and Armstrong, N.A., 1998, The effect of film composition on the diffusion of ethanol through soft gelatin films. International Journal of Pharmaceutics, 161(1), 123-131.

Park, J.W., Park, H.J., Jung, S.T., Rhim, J.W., Park, Y.K. and Hwang, K.T., 1998, Corn-zein laminated carrageenan film for packaging minced mackerels. Korean Journal of Food Science and Technology, 30(6), 1381-1387. (in Korean with English abstract)

Park, M.J., Kim, Y.H., Kim, G.D. and Nam, S.W., 2015, Enzymatic production and adipocyte differentiation inhibition of low-molecular-weight-alginate. Jounal of Life Science, 25(12), 1393-1398. (in Korean with English abstract)

Perron, G., Desnoyers, J.E. and Lara, J., 2002, Permeation of mixture of organic liquids through polymeric membranes. Journal of Applied Polymer Science, 86(1), 195-215.

Rhim, J.W., Hwang, K.T., Park, H.J. and Jung, S.T., 1996, Water-vapor transfer characteristics of carrageenan-based edible film. Korean Journal of Food Science and Technology, 28(3), 545-551. (in Korean with English abstract)

Rhim, J.W., Hwang, K.T., Park, H.J., Kang, S.G. and Jung, S.T., 1998, Liqid penetration characteristics of carrageenanbased edible films. Korean Journal of Food Science and Technology, 30(2), 379-384. (in Korean with English abstract)

Roh, Y.H. and Shin, C.S., 2006, Preparation and characterization of alginate-carrageenan complex film. Journal of Applied Polymer Science, 99(6), 3483-3490.

Shahidi, F. and Han, X.Q., 1993, Encapsulation of food ingredients. Critical Reviews in Food Science and Nutrution, 33(6), 501-547.

Sitaramiah, G.G. and Jorgensen, J.L., 1995, U.S. Patent No. 5,409,977. Washington, DC: U.S. Patent and Trademark Office.

Wang, G., Cheng, J., Zhang, L. and Guo, M., 2012, Physicochemical and functional properties, microstructure, and storage stability of whey protein/polyvinylpyrrolidone based glue sticks. BioResources, 7(4), 5422-5434.

Woo, J.M., Choi, W.G., Kang, J.I., Yeo, I.H. and Kim, T.S., 2010, Anti-arthritic effect of PMO-HYB complex in carrageenan-induced arthritis model. The Korean Society of Food Science and Nutrition, Seoul, October 27-29, 332-332. (in Korean) 